\title{
Effects of Methanol Fraction from Leaves of Schinus terebinthifolius Raddi on Nociception and Spinal-Cord Oxidative Biomarkers in Rats with Neuropathic Pain
}

\author{
Taína Scheid, ${ }^{1}$ Maira Silmara Moraes, ${ }^{1}$ Thiago Pereira Henriques, \\ Ana Paula Konzen Riffel, ${ }^{1}$ Adriane Belló-Klein, ${ }^{1}$ Gilsane Lino Von Poser, ${ }^{2}$ \\ Eduardo Miranda Ethur, ${ }^{3}$ and Wania Aparecida Partata ${ }^{1}{ }^{1}$ \\ ${ }^{1}$ Department of Physiology, Institute of Basic Health Sciences, University of Rio Grande do Sul (UFRGS), Porto Alegre, RS, Brazil \\ ${ }^{2}$ Institute of Pharmacy, University of Rio Grande do Sul (UFRGS), Porto Alegre, RS, Brazil \\ ${ }^{3}$ Department of Exact and Technological Sciences, UNIVATES, Lajeado, RS, Brazil
}

Correspondence should be addressed to Wania Aparecida Partata; partataw@gmail.com

Received 30 January 2018; Accepted 2 April 2018; Published 3 May 2018

Academic Editor: Ke Ren

Copyright (C) 2018 Taína Scheid et al. This is an open access article distributed under the Creative Commons Attribution License, which permits unrestricted use, distribution, and reproduction in any medium, provided the original work is properly cited.

\begin{abstract}
We determined the antioxidant potential of fractions obtained from leaves of Schinus terebinthifolius, a medicinal plant known in Brazil as aroeira, to select the fraction with the best yield and antioxidant performance. These qualities were found in the methanol fraction (MeF), which was administered intraperitoneally $(20 \mathrm{mg} / \mathrm{kg} /$ day) for 3 and 10 days to rats with chronic constriction injury (CCI) of the sciatic nerve, a model of neuropathic pain. The MeF increased the mechanical and thermal thresholds that had been lowered by CCI. In parallel, the lumbosacral spinal cord showed an increase in superoxide dismutase but a decrease in glutathione peroxidase and glutathione-S-transferase activities in saline- and MeF-treated CCI rats. Catalase activity decreased only in salinetreated CCI rats for 10 days. Total thiols decreased in saline- and MeF-treated CCI rats. Ascorbic acid increased in these rats at day 3 but only in saline-treated CCI rats at day 10. No change was found in hydrogen peroxide and lipid hydroperoxide. Open-field and elevated plus-maze tests and blood parameters of liver function did not change. Thus, the MeF from leaves of S. terebinthifolius has an antinociceptive action with no toxic effects, and it affects oxidant biomarkers in the spinal cord of rats with CCI.
\end{abstract}

\section{Introduction}

Neuropathic pain, which arises as a direct consequence of a lesion or disease affecting the somatosensory system, affects $6.0-10 \%$ of the population and negatively impacts the quality of life of patients [1]. The pathophysiological mechanisms are not fully understood [2]. The lack of effective analgesic has impelled a continuing search to find novel molecules with beneficial effects in neuropathic pain. Natural products appear to be the most promising sources of new drugs [3], and the identification of bioactive compounds from plants that may be used to treat neuropathic pain has been a highly active area of pharmaceutical research.

Recently, Piccinelli et al. [4] demonstrated that the essential oil of Schinus terebinthifolius Raddi (Anacardiaceae), a plant native to South America and widely distributed in Brazil, popularly known as aroeira [5], induced antinociception in rats with spared nerve injury-induced neuropathic pain. In pain studies, each animal model has been created with a specific methodology, and the results tend to vary widely with slight changes in the methodology used to induce pain; therefore, it is essential that data from different pain models be reported and interpreted in the context of the specific pain model [6]. An answerable question is whether extracts from S. terebinthifolius have an antinociceptive effect in rats with chronic constriction injury (CCI) of the sciatic nerve. Rats with CCI are one of the most commonly employed animal models of neuropathic pain; CCI simulates the symptoms of chronic nerve compression that correspond to causalgia 
or complex regional pain syndrome in human patients [6].

Saponins, triterpenes, steroids [7], and phenolic compounds [8] have been found in extracts from S. terebinthifolius. Many of these compounds are scavengers of reactive oxygen species (ROS), which are formed in several circumstances including normal cellular metabolism, and participate in a number of functions, for instance, in pain modulation $[9,10]$. Antioxidant agents have been tested to treat neuropathic pain $[11,12]$, but the effects of treatment with extracts from S. terebinthifolius on oxidative biomarkers in nervous tissue have not been investigated.

The present study was designed to investigate the antinociceptive effect of a fraction rich in antioxidant compounds obtained from S. terebinthifolius in rats with CCIinduced neuropathic pain and also to explore the effect of this fraction on prooxidant and antioxidant markers in the lumbosacral spinal cord. Since the yield of the methanol fraction $(\mathrm{MeF})$ was highest and this fraction showed good antioxidant activity, this fraction was chosen to be intraperitoneally administered $(20 \mathrm{mg} / \mathrm{kg} /$ day $)$ for 3 and 10 days in rats with CCI. Then, the activities of superoxide dismutase (SOD), catalase (CAT), glutathione peroxidase (GPx), and glutathione-S-transferase (GST) and the total contents of thiols and ascorbic acid were assessed as antioxidant status markers in the lumbosacral spinal cord of rats with CCI. We also assessed the levels of lipid hydroperoxides and hydrogen peroxide $\left(\mathrm{H}_{2} \mathrm{O}_{2}\right)$ in this tissue, as prooxidant status markers.

Our study also evaluated the locomotor and anxiety-like behaviors of the rats, using open-field (OF) and elevated plus-maze (EPM) tests, respectively; the blood parameters of gamma-glutamyltransferase (GGT), aspartate aminotransferase (AST), alanine aminotransferase (ALT), and bilirubin; and the body weight in naive rats 10 days after treatment, to reveal possible side effects of the treatment.

\section{Materials and Methods}

2.1. Plant Material and Preparation of Fractions. After authorization by the Conselho de Gestão do Patrimônio Genético (CGEN - 010738/2013-4), leaves of S. terebinthifolius were collected at Lajeado, Rio Grande do Sul, Brazil, and authenticated through the Department of Botany, Federal University of the Rio Grande do Sul, where the voucher specimen (number 166738) was deposited. The fractions were obtained by successive extractions of dried and powdered leaves, starting with $\mathrm{n}$-hexane $(\mathrm{He})$ and followed by dichloromethane (Dc), ethyl acetate (Et), and methanol (Me) by static maceration ( $0.5 \mathrm{~L}$ of solvent, daily exchanges for 12 days, for each solvent). The extractive solutions were evaporated to dryness under vacuum at low temperature $\left(42 \pm 2^{\circ} \mathrm{C}\right)$ and stored at $8^{\circ} \mathrm{C}$. The yields of the fractions were $\mathrm{HeF}$ (3.84\%), DcF (1.49\%), EtF (1.63\%), and $\mathrm{MeF}$ (5.30\%).

\subsection{Antioxidant Properties of Schinus terebinthifolius Fractions}

2,2-Diphenyl-1-picrylhydrazyl (DPPH) Radical Scavenging Activity. The free radical scavenging activity of the fractions and antioxidant standards ascorbic acid and butylated hydroxytoluene (BHT) in different concentrations $(25-500 \mu \mathrm{g} / \mathrm{mL})$ were measured [13]. All experiments were repeated three times independently. The percentage inhibition of DPPH free-radical scavenging activity was calculated using the following equation: DPPH inhibition\% $=\left[\left(A_{0}-A_{1}\right) / A_{0} \times 100\right]$, where $A_{0}$ is the absorbance of the control reaction $(3 \mathrm{~mL}$ of methanol and $1 \mathrm{~mL}$ of DPPH solution, without a sample of extracts) and $A_{1}$ is the absorbance in the presence of the fractions or standards. The $\%$ inhibition data were then plotted versus the concentration and graphed, and the $\mathrm{IC}_{50}$ (half-maximal inhibitory concentration) value was calculated by linear regression analysis.

Hydroxyl Radical Scavenging Activity. This assay quantified hydroxyl radicals indirectly through the 2-deoxy-Dribose degradation product, malondialdehyde, as described by Chobot [14], using fractions and BHT in different concentrations $(25-250 \mu \mathrm{g} / \mathrm{mL})$. Assays were performed in triplicate and the results were expressed in $\mathrm{IC}_{50}$ values.

Total Reactive Antioxidant Potential (TRAP). The TRAP was determined by measuring the chemiluminescence (CL) intensity of luminol induced by ABAP, as described by Dresch et al. [15]. The CL was measured in a liquid scintillation counter (LKB Rack Beta Liquid Scintillation Spectrometer1215, Sweden) using fractions at concentrations of 2.5, 5.0, 10.0 , and $25.0 \mu \mathrm{g} / \mathrm{mL}$. The Trolox equivalents of the sample were calculated using a standard curve of Trolox.

Phytochemical Screening. Qualitative phytochemical analysis of Schinus terebinthifolius fractions was carried out by TLC (Silicagel, $60 \mathrm{~F}_{254}$ ) to evaluate the presence of alkaloids, anthracene derivatives, triterpenes/steroids, phenolic compounds in general, coumarins, flavonoids, and saponins as described by Wagner and Bladt [16].

Determination of Total Phenolic Content. The total phenolic content was determined as described by Siatka and Kašparová [13]. Results were expressed as milligram-equivalents of gallic acid per g of extract (EGA mg/g). All analyses were carried out in triplicate.

2.3. Animals and Treatment. Animal procedures were approved by the Ethics Committee of the Federal University of Rio Grande do Sul (\# 19388). Male Wistar rats (230-290 g) were randomly and blindly divided into three experimental groups (naive, Sham, and CCI), and each was further divided into two subgroups ( $n=6 /$ subgroup), which received $\mathrm{MeF}$ at a dose of $20 \mathrm{mg} / \mathrm{kg} / \mathrm{day}$ or $0.9 \%$ saline solution, intraperitoneally, for 3 and $10 \mathrm{~d}$. The choice of dose was guided by previous studies that also employed alcoholic extracts of S. terebinthifolius and showed anti-inflammatory effects [17] and absence of genotoxic and mutagenic effect [18]. The time of study ( 3 and 10 days) was chosen because our previous studies showed that the spinal-cord oxidative biomarkers changed in rats with CCI-induced neuropathic pain [12]. Since the literature contains study showing that the extract of $S$. terebinthifolius may be used with both 
routes of administration (oral and intraperitoneal) [19], intraperitoneal administration was chosen because the basic goal of this drug delivery is to increase the local drug concentration and the duration of drug exposure while decreasing systemic drug toxicity [20]. The administration started on the day of surgery (after recovery from anesthesia) and was performed daily at 17:00 $\mathrm{h}$ by the same researcher.

2.4. Induction of Chronic Constriction Injury (CCI). After anesthesia (90 $\mathrm{mg} / \mathrm{Kg}$ ketamine and $10 \mathrm{mg} / \mathrm{Kg}$ xylazine), the right common sciatic nerve was exposed proximal to its trifurcation via a mid-thigh incision, and four ligatures (4.0 Shalon Chromic Catgut) were tied loosely around it as described by Bennett and Xie [21], with slight modifications [12]. After nerve ligation, the muscle and skin layer were immediately sutured with thread and a topical antibiotic was applied. To expose the sciatic nerve in Sham rats, all surgical procedures involved in the CCI were used except the ligature.

2.5. Thermal and Mechanical Thresholds. Rats were subjected to sensitivity assessments before the surgical procedure (day 0 ) and at $3,5,7$, and 10 days after surgery. Thermal hyperalgesia was measured by placing the rats on a hot plate maintained at $50^{\circ} \mathrm{C}\left( \pm 2^{\circ} \mathrm{C}\right)$. Withdrawal latency was considered as when the animal jumped or licked a hind paw, independently of the side. A cutoff time of $30 \mathrm{~s}$ was employed to prevent tissue injury.

To measure mechanical sensitivity, the responses of the injured hindpaw to electronic von Frey apparatus (Insight, Brazil) were measured. For this, increasing pressure was applied against the plantar surface. A positive response was indicated by an abrupt withdrawal of the paw, and the intensity of the pressure was automatically recorded (in grams). A single trial consisted of five applications of the plastic tip, once every $5-10 \mathrm{~s}$. The mean of five readings was taken as the threshold for a particular timing trial.

Behavioral assessments were conducted at the same time of day $(08: 00 \mathrm{~h})$ and by the same researcher.

2.6. Locomotor and Anxiety-Like Behaviors. Naive rats were divided into two groups $(n=12 /$ group $)$ that received saline or MeF (20 mg/kg/d, intraperitoneally). The tests were performed in the morning, but on separate days to avoid stress to the animals. The OF were performed after 9 days of treatment (day 10 after $\mathrm{CCI}$ ) and the EPM were conducted after 10 days of injections (day 11 after CCI). The EPM was assessed as described by de Souza et al. [22]. For the OF, an apparatus that consists of a brightly illuminated circular arena ( $90 \mathrm{~cm}$ diameter, $50 \mathrm{~cm}$-high walls) with the floor marked in 12 sectors by concentric circles was used.

2.7. Preparation of Tissue Samples. The body weight was evaluated in naive rats that received saline and $\mathrm{MeF}(20 \mathrm{mg} / \mathrm{kg} / \mathrm{d})$ for 10 days. The weight of animals was recorded before the start of the injections (day 0 ) and at the end of the treatment period (day 11).

All rats were killed by decapitation and blood and lumbosacral spinal cord were promptly collected. The blood was centrifuged (Sorvall RC 5B, Rotor SM 24) for 20 min at
$1000 \times \mathrm{g}$ and the plasma was used to determine GGT, AST, ALT, and bilirubin (Labtest). Commercially available kits (LABTEST) were used for these assays.

The spinal cord was immediately divided into two parts. One part was cooled in liquid nitrogen and processed to determine $\mathrm{H}_{2} \mathrm{O}_{2}$. Another part was homogenized in 1.15\% $\mathrm{KCl}$ diluted $1: 5(\mathrm{w} / \mathrm{v})$ containing $1 \mathrm{mmol} / \mathrm{L}$ phenylmethylsulfonyl fluoride. The homogenates were centrifuged at $800 \times \mathrm{g}$ for $20 \mathrm{~min}$ at $4^{\circ} \mathrm{C}$ to remove the nuclei and cell debris. The supernatant was frozen at $-80^{\circ} \mathrm{C}$ and used for assays of the antioxidant parameters.

2.8. Determination of Antioxidant Enzyme Activities. The activity of SOD was measured based on its action to neutralize the superoxide radicals to prevent oxidation of adrenalin to adrenochrome, a colorful byproduct that can be measured at $480 \mathrm{~nm}$. The reaction medium contained glycine buffer $(50 \mathrm{mM}, \mathrm{pH} 11.3)$ and adrenalin $(60 \mathrm{mM}, \mathrm{pH} 2.0)$ and the results were expressed as units per milligram of protein [23].

The CAT activity was determined at $240 \mathrm{~nm}$ in a reaction medium containing phosphate buffer $(0.1 \mathrm{M}, \mathrm{pH} 7.4)$ and $\mathrm{H}_{2} \mathrm{O}_{2}(0.88 \mathrm{M})$, and the results were expressed as pmol of $\mathrm{H}_{2} \mathrm{O}_{2}$ reduced per minute per milligram of protein [24].

The GPx activity was measured at $340 \mathrm{~nm}$ and the reaction medium contained phosphate buffer $(140 \mathrm{mM}, \mathrm{pH}$ = 7.5), EDTA $(1 \mathrm{mM})$, NADPH $(0.24 \mathrm{mM})$, sodium azide $(1 \mathrm{mM})$, GSH $(5 \mathrm{mM})$, glutathione reductase $(0.25 \mathrm{U} / \mathrm{mL})$, and tertiary butyl hydroperoxide $(0.5 \mathrm{mM})$ [25]. Results were expressed as nmoles of peroxide/reduced hydroperoxide per minute per milligram of protein.

GST activity, expressed as nanomoles per milligram of protein, was measured by the rate of formation of dinitrophenyl-S-glutathione at $340 \mathrm{~nm}$ [26].

2.9. Determination of Ascorbic Acid and Total Thiol Levels. Ascorbic acid (AA) concentration was determined according to method described by Roe and Kuether [27]. The assay mixture contained $0.3 \mathrm{~mL}$ homogenate treated with charcoal and filtered, $0.01 \mathrm{~mL} 10 \%$ thiourea, and $0.075 \mathrm{~mL} 2 \% 2,4$ Dinitrophenylhydrazine and was incubated at $37^{\circ} \mathrm{C}$ for $3 \mathrm{~h}$. Following this, color was produced by adding $0.375 \mathrm{~mL}$ $85 \%$ sulfuric acid and the absorbance was read at $540 \mathrm{~nm}$. Standard curve was prepared by using different concentration of $\mathrm{AA}$ and slope was used to express amount of $\mathrm{AA}$ as micromole of AA per milligram of protein.

The total thiol content was determined as described by Aksenov and Markesbery [28]. The reaction medium contained phosphate/EDTA buffer $(\mathrm{pH}=7.5)$ and $5,5^{\prime}$-dithiobis (2-nitrobenzoic) acid (DTNB, $10 \mathrm{mM})$. After 30 minutes of incubation, the absorbances were read at $412 \mathrm{~nm}$. Results were expressed as micromoles of TNB per milligram of protein.

2.10. Determination of $\mathrm{H}_{2} \mathrm{O}_{2}$ and Lipid Hydroperoxides Levels. The assay was based on horseradish peroxidase- (HRPO-) mediated oxidation of phenol red by $\mathrm{H}_{2} \mathrm{O}_{2}$, leading to the formation of a compound that is absorbed at $610 \mathrm{~nm}$. Sections of fresh tissue from the lumbosacral spinal cord were incubated for $30 \mathrm{~min}$ at $37^{\circ} \mathrm{C}$ in $10 \mathrm{mmol} / \mathrm{L}$ phosphate buffer (140 $\mathrm{mmol} / \mathrm{L} \mathrm{NaCl}$ and $5 \mathrm{mmol} / \mathrm{L}$ dextrose). The supernatants 
TABLE 1: Antioxidant properties and chemical compounds of the fractions of Schinus terebinthifolius.

\begin{tabular}{|c|c|c|c|c|c|}
\hline & \multicolumn{4}{|c|}{ Schinus terebinthifolius fractions } & \multirow{2}{*}{$\begin{array}{l}\text { Antioxidant } \\
\text { standard }\end{array}$} \\
\hline & $\mathrm{HeF}$ & $\mathrm{DcF}$ & EtF & $\mathrm{MeF}$ & \\
\hline $\begin{array}{l}\text { Scavenging activity against } \\
\text { hydroxyl radical in } \mathrm{IC}_{50}\end{array}$ & $59.09 \pm 4.8^{\mathrm{a}}$ & $146.21 \pm 6.8^{\mathrm{b}}$ & $32.57 \pm 0.8^{c}$ & $134.09 \pm 7.0^{\mathrm{b}}$ & $\begin{array}{c}\text { BHT } \\
46.21 \pm 0.8^{\mathrm{a}, \mathrm{c}} \\
\end{array}$ \\
\hline $\begin{array}{l}\text { Scavenging activity against } \\
\text { DPPH radical in } \mathrm{IC}_{50}\end{array}$ & $596.2 \pm 0.4^{\mathrm{a}}$ & $238.99 \pm 0.2^{\mathrm{b}}$ & $5.19 \pm 0.1^{c}$ & $3.00 \pm 0.1^{\mathrm{d}}$ & $\begin{array}{c}\text { BHT } \\
6.25 \pm 0.1^{\mathrm{e}} \\
\text { AA } \\
2.43 \pm 0.1^{\mathrm{f}}\end{array}$ \\
\hline \multicolumn{6}{|c|}{ Total reactive antioxidant potential (TRAP) } \\
\hline $2.5 \mu \mathrm{g} / \mathrm{mL}$ & $1.49 \pm 0.1^{\mathrm{a}}$ & $2.32 \pm 0.1^{\mathrm{b}}$ & $1.51 \pm 0.1^{\mathrm{b}}$ & $3.22 \pm 0.1^{\mathrm{c}}$ & ND \\
\hline $5.0 \mu \mathrm{g} / \mathrm{mL}$ & $1.73 \pm 0.1^{\mathrm{a}}$ & $2.39 \pm 0.2^{\mathrm{a}}$ & $2.18 \pm 0.1^{\mathrm{a}}$ & $4.02 \pm 0.4^{\mathrm{b}}$ & ND \\
\hline $10.0 \mu \mathrm{g} / \mathrm{mL}$ & $1.19 \pm 0.1^{\mathrm{a}}$ & $2.42 \pm 0.1^{\mathrm{b}}$ & $3.50 \pm 0.2^{\mathrm{b}, \mathrm{c}}$ & $4.90 \pm 0.3^{\mathrm{c}}$ & ND \\
\hline $25.0 \mu \mathrm{g} / \mathrm{mL}$ & $1.27 \pm 0.1^{\mathrm{a}}$ & $2.63 \pm 0.1^{\mathrm{b}}$ & $4.265 \pm 0.1^{\mathrm{c}}$ & $5.805 \pm 0.1^{\mathrm{d}}$ & ND \\
\hline Total phenol content & $7.49 \pm 1.0^{\mathrm{a}}$ & $32.27 \pm 8.4^{\mathrm{a}}$ & $357.62 \pm 19^{\mathrm{b}}$ & $406.35 \pm 16.1^{\mathrm{c}}$ & ND \\
\hline Anthraquinones & + & + & + & + & \\
\hline Triterpenes/steroids & + & + & + & + & \\
\hline Phenolic compounds & + & + & + & + & \\
\hline Flavonoids & - & - & + & + & \\
\hline Saponins & - & - & + & + & \\
\hline Coumarins & - & - & - & + & \\
\hline Alkaloids & - & - & - & - & \\
\hline
\end{tabular}

Values are expressed as mean \pm S.E. Values with different superscript letters in the same row are significant different at $P<0.05$. ND: not detected. The units are expressed as follows: TRAP ( $\mu \mathrm{M}$ trolox equivalents); DPPH and hydroxyl $(\mu \mathrm{g} / \mathrm{mL})$; total phenol content (mg EGA/g fraction). +: present; -: absent.

were transferred to tubes with $0.28 \mathrm{mmol} / \mathrm{L}$ phenol red and $8.5 \mathrm{U} / \mathrm{mL}$ HRPO. After $5 \mathrm{~min}$ incubation, $1 \mathrm{~mol} / \mathrm{L} \mathrm{NaOH}$ was added, and the solution was read at $610 \mathrm{~nm}$. The results were expressed in $\mu$ moles $\mathrm{H}_{2} \mathrm{O}_{2}$ per mg tissue [29].

The lipid hydroperoxides were measured by oxidation of $\mathrm{Fe}^{2+}$ by $\mathrm{LOOH}$ in an acid medium containing xylenol orange dye, which forms a complex with $\mathrm{Fe}^{3+}$, as described by Jiang et al. [30]. Results are expressed in nmol per g tissue.

2.11. Protein Measurement. Protein was measured by the method of Lowry et al. [31], using bovine serum albumin as the standard.

2.12. Statistical Analysis. Data were analyzed by two independent researchers; one was blinded to treatment. Data for antioxidant assays of the extract were analyzed by oneway ANOVA followed by Tukey's post hoc test. Pearson's correlation coefficient $(r)$ was calculated between total phenolic content and the methods used to assess the antioxidant activity. Data for von Frey and hot-plate tests were analyzed by repeated-measures ANOVA followed by Tukey's test. The results for EPM, plasma parameters, and body weight were analyzed by unpaired Student's $t$-test, while results of the OF were assessed by Mann-Whitney $U$ test. Data for spinal-cord oxidative biomarkers were compared by three-way ANOVA followed by Holm-Sidak post hoc test. Differences were considered statistically significant when $P$ was $<0.05$. All statistical analyses were carried out with the software Origin 8 .

\section{Results}

3.1. Antioxidant Properties of Schinus terebinthifolius Fractions. In the hydroxyl scavenging assay, the $\mathrm{HeF}$ and $\mathrm{EtF}$ showed $\mathrm{IC}_{50}$ values similar to the antioxidant standard. The DcF and MeF showed higher values $(P<0.001)$ (Table 1$)$. In the DPPH assay, the MeF and EtF showed excellent scavenging activities, superior to BHT and similar to ascorbic acid. The HeF and DcF, in turn, showed weaker activities, with $\mathrm{IC}_{50}$ values at least 80 times higher than the other fractions $(P<0.001)$. In the TRAP assay, the greatest potential was found in the MeF, followed by the EtF, DcF, and HeF $(P<$ $0.001)$. The highest content of total phenols was found in the $\mathrm{MeF}$, while the lowest occurred in the DcF and $\operatorname{HeF}(P<$ 0.001). A high linear correlation $(r>0.98 ; P<0.05)$ was observed between TRAP values and phenolic content. No linear correlation was found in other antioxidant tests.

3.2. Phytochemical Screening of Schinus terebinthifolius Fractions. Anthraquinones and triterpenes/steroids were present in all fractions. Flavonoids and saponins were present only in the EtF and MeF. Coumarins were found only in the MeF (Table 1).

3.3. Behavioral Assessment. After CCI, no rat displayed gross deficits in motor behavior that might have influenced the assessment of thermal and mechanical sensitivities. No significant change was found in the naive group throughout the experimental period (Figure 1). 

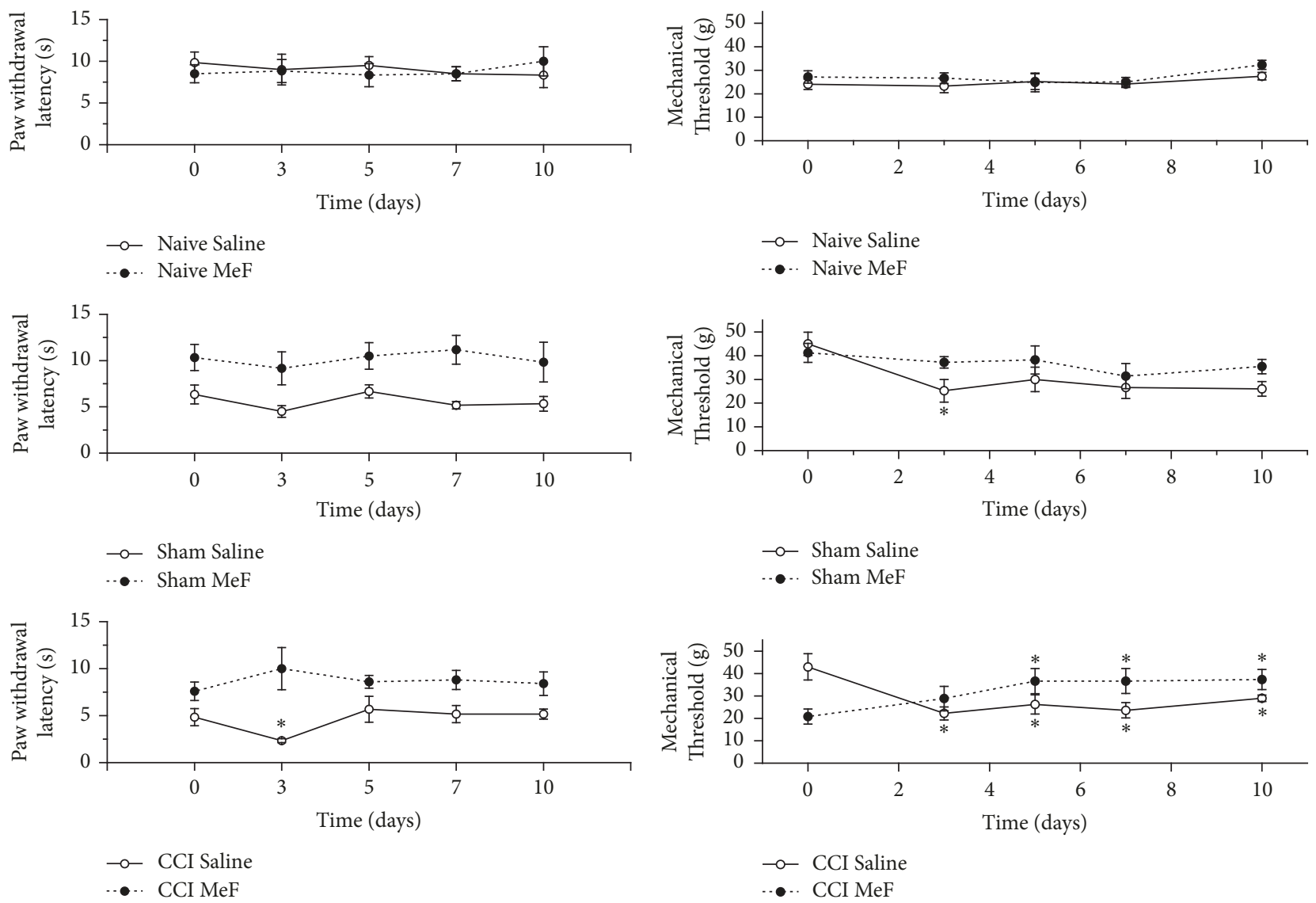

(a)

(b)

FIGURE 1: Assessment of behavioral hypersensitivity after chronic constriction injury (CCI) of the sciatic nerve in rats treated with methanol fraction (MeF) $(20 \mathrm{mg} / \mathrm{kg} / \mathrm{day}$, i.p.) from leaves of Schinus terebinthifolius for 10 days. (a) Latency time against heat stimuli; (b) mechanical hypersensitivity. Data represent the means $\pm \operatorname{SEM}(n=6$ for each group). * indicates a significant difference compared to pre-nerve lesion values (repeated-measures ANOVA followed by Tukey post hoc test, $P<0.05$ ).

At day 3 after surgery, the paw-withdrawal latency decreased $(48.2 \%)$ in the saline-treated CCI rats, while no significant reduction was found in the MeF-treated CCI rats, compared to the pre-nerve-lesion level (Figure 1(a)). At days 5,7 , and 10 , no significant change was found in the salineand MeF-treated CCI rats compared to before nerve lesion. Despite baseline differing between saline- and MeF-treated sham rats, sham groups showed no significant changes in paw-withdrawal latency throughout the experimental periods.

The mechanical threshold in the saline-treated CCI rats decreased around $51 \%$ at day 3 compared to pre-nerve-lesion levels. The same response was found at days 5, 7, and 10 . However, the MeF-treated CCI rats showed no decrease in the mechanical threshold (Figure 1(b)). At day 3 after surgery, the mechanical threshold of the MeF-treated CCI rats was similar to the pre-nerve-lesion threshold. However, a significant increase occurred at later time points: at 5, 7, and 10 days after surgery, the mechanical threshold was increased (76\%) in the MeF-treated CCI rats compared to before nerve lesion.

Similar to the saline-treated CCI rats, the mechanical threshold in the saline-treated Sham rats also showed a reduction (56\%), although only at day 3 compared to preprocedure levels. No significant difference between the preand post-procedure levels was found at days 5, 7, and 10 . The MeF-treated Sham rats showed no decrease in the mechanical threshold 3 days after surgery (Figure 1(b)).

No significant difference was found in the EPM and OF results for the naive rats treated with saline or MeF for 10 days (Table 2).

3.4. Effects on Biochemical Parameters of the Spinal Cord. At days 3 and 10 after CCI, the spinal-cord SOD activity increased by approximately $60 \%$ in the saline- and MeFtreated CCI rats. The saline- and MeF-treated Sham rats also showed significant increases in this parameter at days 3 and 10 , compared to the naive group (Figure $2(\mathrm{a})$ ). While the increase was 42 and 54\% in the saline- and MeF-treated Sham rats, respectively, at day 3 , the corresponding percentages were 46 and $78 \%$ at day 10 .

At day 3, no significant change was found in spinal-cord CAT activity in the saline- and MeF-treated CCI rats. While this treatment did not produce a significant change in the MeF-treated CCI rats at day 10, the saline-treated CCI rats 
TABLE 2: Effect of methanol fraction (MeF) from Schinus terebinthifolius (20 mg/kg/day) on locomotor activity and anxiety-like behaviors in naive rats.

\begin{tabular}{|c|c|c|c|c|c|c|c|c|}
\hline \multirow{3}{*}{ Parameters } & \multicolumn{7}{|c|}{ Elevated plus-maze test (EPM) } & \multirow{3}{*}{$P$ values } \\
\hline & \multicolumn{4}{|c|}{ Saline } & \multicolumn{3}{|c|}{$\mathrm{MeF}$} & \\
\hline & \multicolumn{2}{|r|}{ Mean } & & $\pm \mathrm{SE}$ & \multicolumn{2}{|c|}{ Mean } & \multirow{2}{*}{$\frac{ \pm \mathrm{SE}}{4.76}$} & \\
\hline \% Time in open arms (s) & & 13.29 & & 3.13 & & & & 0.472 \\
\hline \% Time in closed arms (s) & & 86.71 & & 3.13 & & & 4.76 & 0.472 \\
\hline$\%$ Entries in open arms & & 21.49 & & 3.63 & & & 4.12 & 0.753 \\
\hline$\%$ Entries in closed arms & & 78.51 & & 3.63 & & & 4.12 & 0.753 \\
\hline Number of rearings in open arms & & 0.00 & & 0.00 & & & 0.00 & - \\
\hline Number of head dips & & 7.42 & & 2.36 & & & 1.82 & 1.0 \\
\hline Risk assessment (s) & & 16.53 & & 4.27 & & & 3.41 & 0.612 \\
\hline \multirow{3}{*}{ Parameters } & \multicolumn{7}{|c|}{ Open field test (OF) } & \multirow{3}{*}{$P$ values } \\
\hline & \multicolumn{4}{|c|}{ Saline } & \multicolumn{3}{|c|}{$\mathrm{MeF}$} & \\
\hline & Median & & $25 \%$ & $75 \%$ & Median & $25 \%$ & $75 \%$ & \\
\hline Total crossings & 52.0 & & 38.0 & 64.0 & 56.0 & 40.0 & 72.0 & 0.532 \\
\hline Peripheral crossings & 45.0 & & 35.0 & 50.0 & 44.0 & 36.0 & 50.0 & 0.818 \\
\hline Central crossings & 2.0 & & 1.0 & 5.0 & 4.0 & 0.0 & 8.0 & 0.447 \\
\hline Time in central area (s) & 3.6 & & 0.7 & 7.2 & 9.1 & 1.7 & 24.6 & 0.189 \\
\hline Latency to $1^{\circ}$ crossing (s) & 7.1 & & 3.0 & 11.1 & 6.1 & 5.0 & 10.0 & 0.948 \\
\hline Latency to enter central area (s) & 110.0 & & 47.1 & 154.1 & 68.1 & 62.1 & 158.0 & 0.844 \\
\hline Rearings & 14.0 & & 11.0 & 23.0 & 23.0 & 12.0 & 29.0 & 0.292 \\
\hline Freezing (s) & 0.0 & & 0.0 & 10.8 & 0.0 & 0.0 & 0.0 & 0.108 \\
\hline Grooming (s) & 3.9 & & 0.0 & 8.1 & 1.0 & 0.0 & 15.0 & 0.946 \\
\hline
\end{tabular}

Results are expressed as means \pm SE for EPM; median and percentiles for OF, $n=12$ rats. No significant differences were found between the groups (Student's $t$-test, for EPM; Mann-Whitney $U$ test, for OF; $P<0.05)$.

showed a decrease (46\%) at this time point (Figure 2(b)). In Sham rats, CAT activity increased 48 and $51 \%$ in the spinal cord of the rats that received saline and $\mathrm{MeF}$ for 3 days, respectively. However, CAT activity decreased by around $60 \%$ in the saline- and MeF-treated Sham rats at day 10.

At days 3 and 10 after CCI, GPx activity was significantly reduced in the spinal cord of the saline- and MeF-treated CCI rats (Figure 2(c)). In Sham rats, while GPx activity decreased in animals that received saline for 3 days, the activity of this enzyme showed no significant change in the MeF-treated rats at this time point. At day 10, GPx activity decreased in both the saline- and MeF-treated Sham rats.

The GST activity decreased around $45 \%$ in the spinal cord from CCI rats that received $\mathrm{MeF}$ and saline for 3 and 10 days, compared to naive rats. In the Sham rats the activity of this enzyme also decreased. The reduction was approximately $50 \%$ in the saline- and MeF-treated Sham rats after 3 and 10 days (Figure 2(d)).

The ascorbic-acid content increased more than $50 \%$ in the spinal cord of CCI rats that received $\mathrm{MeF}$ and saline for 3 days, compared to naive rats. At day 10, only the saline-treated CCI rats showed an increase in ascorbic-acid levels. In the spinal cord of the MeF-treated CCI rats, the ascorbic-acid level was similar to that found in naive rats (Figure 3(a)). No significant change was found in Sham rats.

At days 3 and 10 after CCI, the total thiol was reduced in the spinal cord of the saline- and MeF-treated rats. At day
3 , the decrease was around $43 \%$ in the spinal cord of these rats. At day 10 , the decrease was $50 \%$ in the spinal cord of the saline-treated CCI rats, but approximately $28 \%$ in the spinal cord of the MeF-treated CCI rats (Figure 3(b)). In Sham rats, the total thiol content decreased in the spinal cord of the rats that received saline for 3 days, but increased (57\%) in the MeF-treated rats. At day 10, there was a reduction of $43 \%$ in the spinal-cord total thiol content in the saline- and MeFtreated Sham rats.

No significant change was found in $\mathrm{H}_{2} \mathrm{O}_{2}$ levels in the spinal cord from the saline- and MeF-treated CCI rats after 3 and 10 days (Figure $3(\mathrm{c})$ ). The MeF administration did not change the $\mathrm{H}_{2} \mathrm{O}_{2}$ level in the spinal cord from Sham rats that received treatment for 3 and 10 days. However, this prooxidant marker increased 122 and $88 \%$ in rats that received saline for 3 and 10 days, respectively.

Despite high variation, there was no significant difference in spinal-cord lipid hydroperoxide levels in CCI and Sham rats that received MeF and saline for 3 and 10 days (Figure 3(d)).

3.5. Effect on Blood Parameters and Body Weight. GGT, AST, ALT, and bilirubin levels did not change significantly with $\mathrm{MeF}$ administration (Table 3). Similarly, the MeF did not induce changes in body weight (initial: $234 \pm 7 \mathrm{~g}$; final: $256 \pm$ $5 \mathrm{~g}$ ) compared to the saline group (initial: $245 \pm 11 \mathrm{~g}$; final: $287 \pm 14 \mathrm{~g})$. 


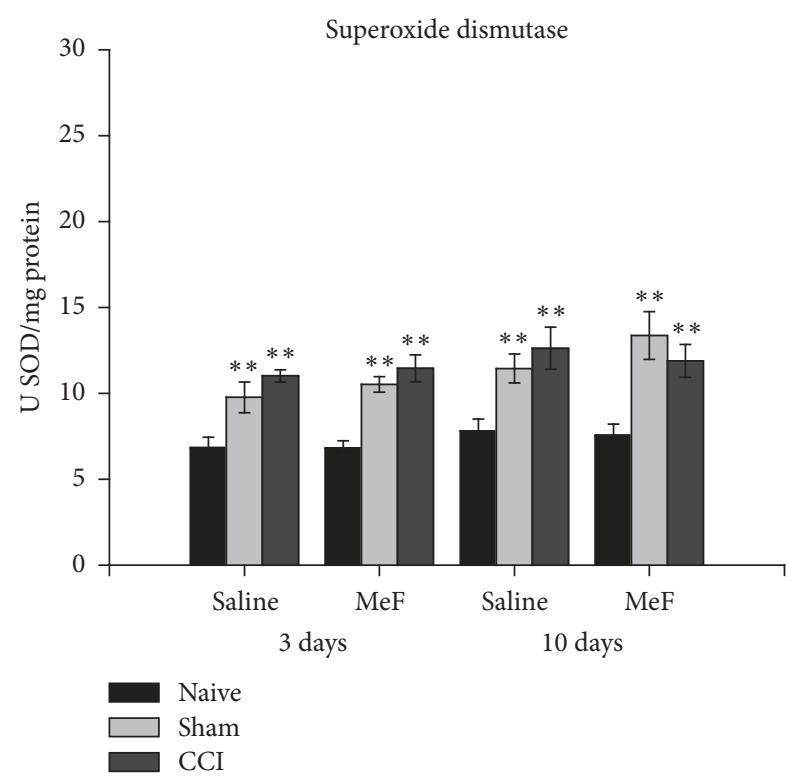

(a)

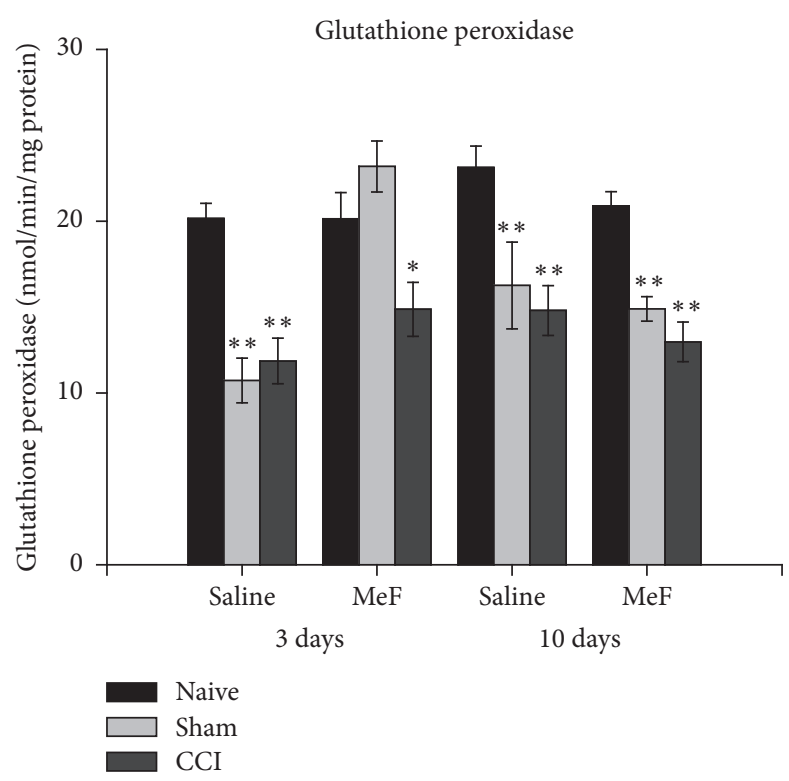

(c)

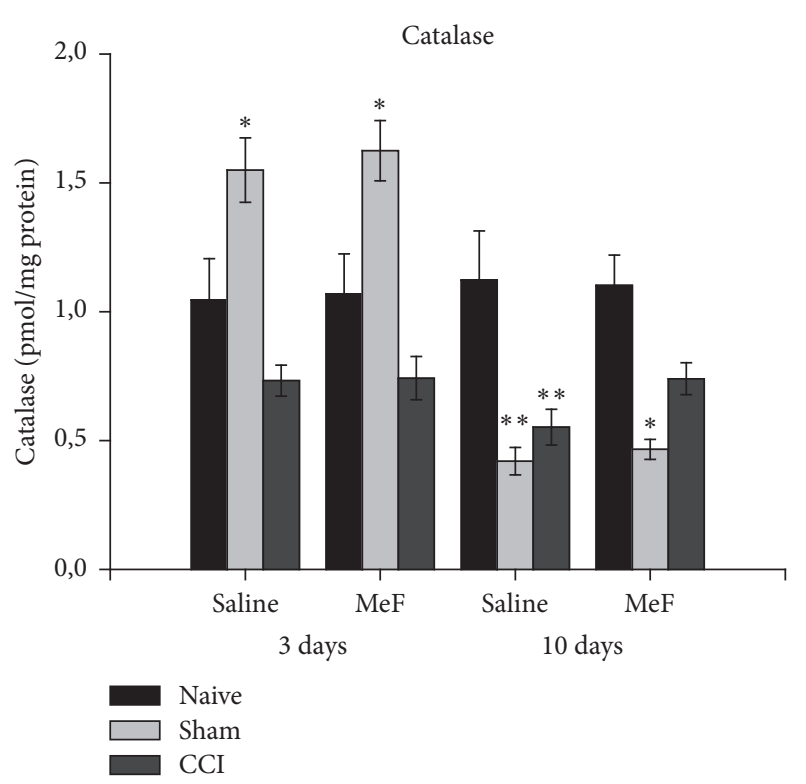

(b)

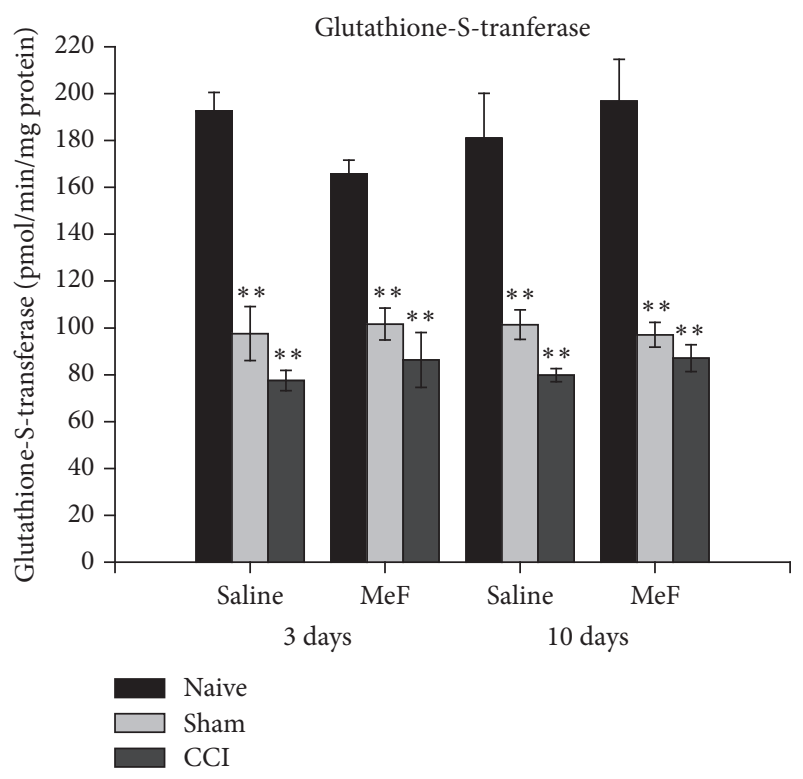

(d)

FIgURE 2: Activities of (a) superoxide dismutase, (b) catalase, (c) glutathione peroxidase, and (d) glutathione-S-tranferase in spinal cord of rats treated with methanol fraction $(\mathrm{MeF})(20 \mathrm{mg} / \mathrm{kg} / \mathrm{d})$ or saline for 3 and 10 days. Data represent mean \pm SEM $(n=6 /$ group $) . *$ indicates a significant difference compared to naive and Sham or naive and CCI at same treatment and experimental period. $* *$ indicates a significant difference compared to naive at same treatment and experimental period $(P<0.05$; three-way ANOVA followed by Holm-Sidak post hoc test).

\section{Discussion}

The present study showed that extracts prepared from $S$. terebinthifolius leaves, particularly the MeF, have high antioxidant potential. The occurrence of an antioxidant potential in extracts from $S$. terebinthifolius is in line with the previous study by El-Massry et al. [8].

Our study showed for the first time that administration of the MeF induces attenuation of CCI-induced neuropathic pain. Since antioxidants are candidates for the treatment of neuropathic pain $[11,12]$, it is possible that the increase in the thermal and mechanical sensitivities of the MeFtreated CCI rats is related to the antioxidant potential of the MeF. However, the screening also indicated the presence of triterpenes/steroids and saponins in this fraction. These kinds of compounds also show an ameliorative effect on neuropathic pain [32], and therefore may also be contributing to the antinociceptive effect of the MeF. Another contributor 


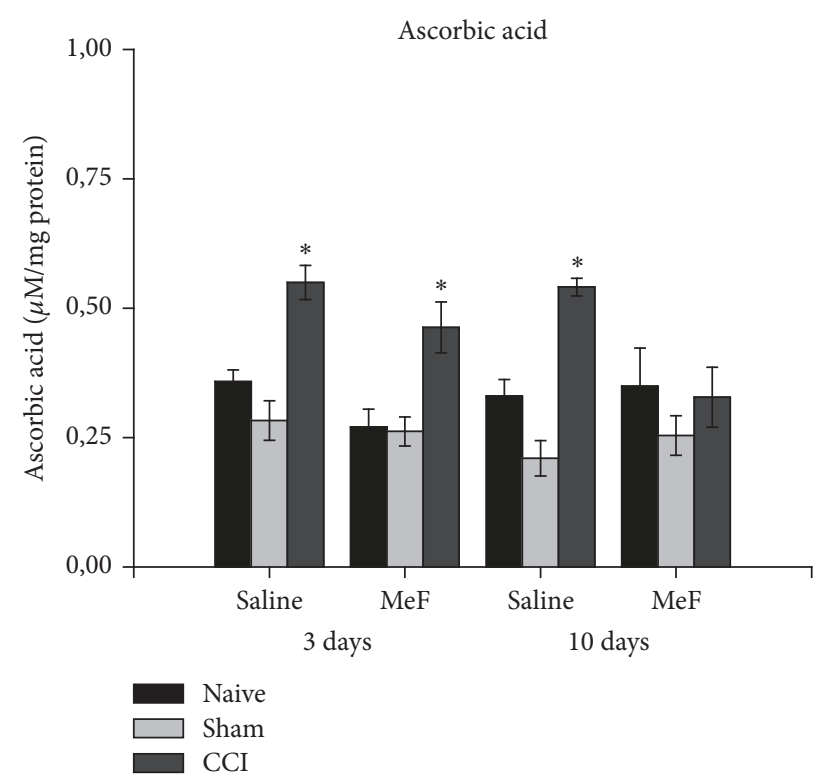

(a)

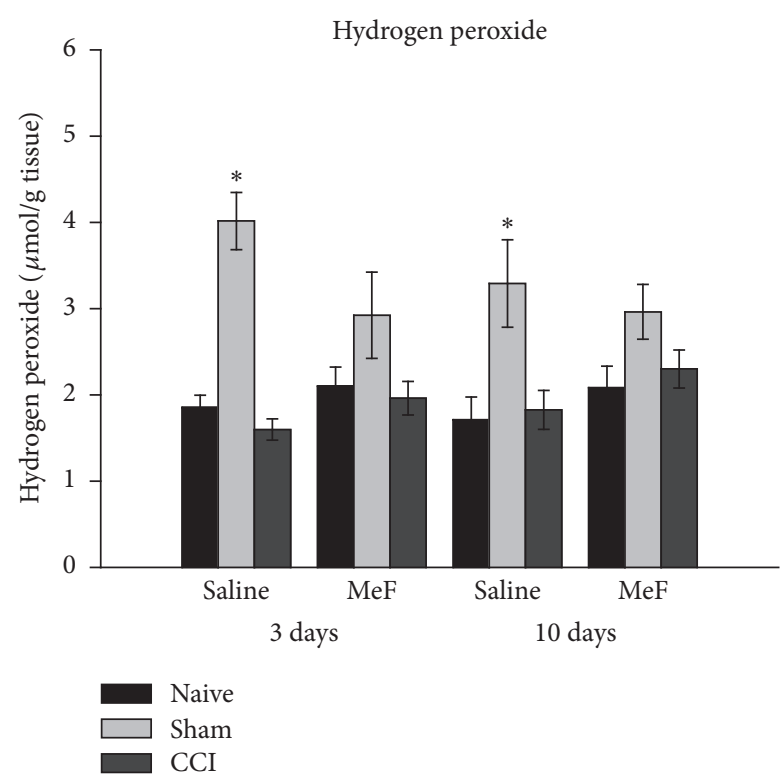

(c)

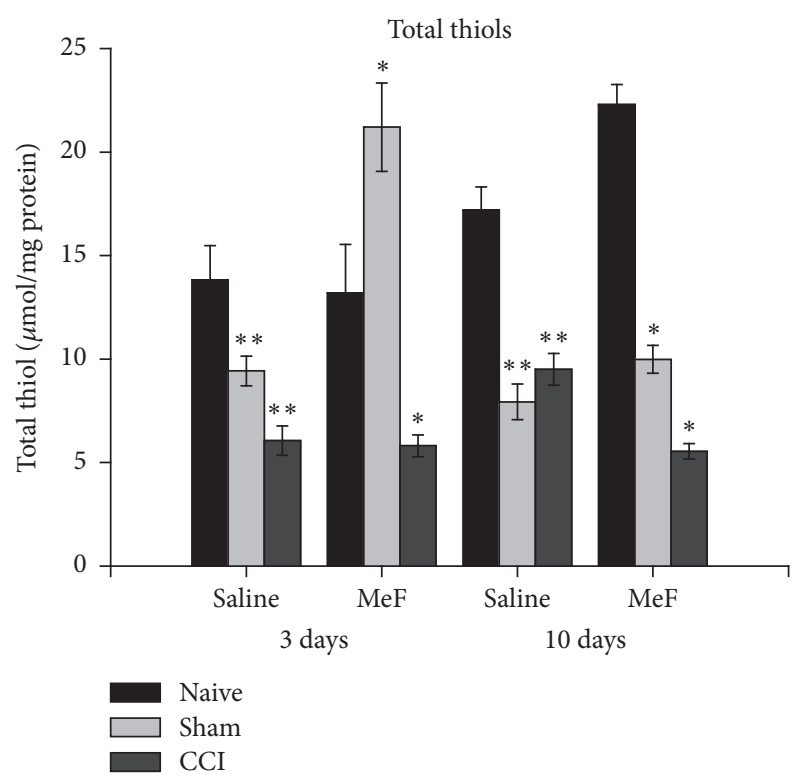

(b)

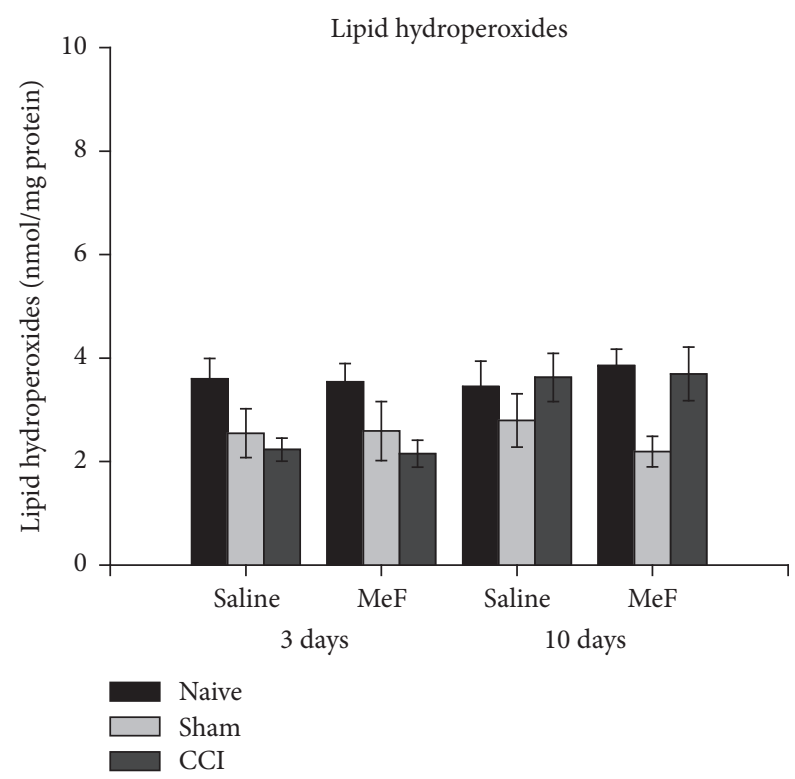

(d)

FiguRe 3: Ascorbic acid (a), total thiols (b), hydrogen peroxide (c), and lipid hydroperoxides (d) levels in spinal cord of rats treated with methanol fraction $(\mathrm{MeF})(20 \mathrm{mg} / \mathrm{kg} / \mathrm{d})$ or saline for 3 and 10 days. Data represent mean \pm SEM $(n=6 /$ group $)$. * indicates a significant difference compared to naive and Sham or naive and CCI at same treatment and experimental period. $* *$ indicates a significant difference compared to naive at same treatment and experimental period $(P<0.05$; three-way ANOVA followed by Holm-Sidak post hoc test).

to antinociception may be the anti-inflammatory effect of $S$. terebinthifolius. Some compounds of extracts from this plant appear to have anti-inflammatory activity [33]. Câmara et al. [34] demonstrated that reduction of the inflammatory process contributes to antinociception in rats with CCI. Thus, more tests are necessary to better characterize the chemical compounds of the MeF that may be contributing to antinociceptive effect of this fraction in rats with CCI.

The reduction in the mechanical threshold in the Sham rats may be due to the procedures involving manipulation of deep tissues, such as muscles and adjacent connective tissue, which induce pain [10]. Since MeF administration induced an antinociceptive effect in these animals, this result also reinforces the antinociceptive effect of the $\mathrm{MeF}$ in pain conditions. The lack of significant changes in the pawwithdrawal latency in the saline-treated CCI rats 5, 7, and 10 days after the surgery suggests a reversion of the thermal hyperalgesia, but we do not believe that a total reversion of symptoms occurs within 5 days. This may indicate a limitation of the test used in our study. 
TABle 3: Effect of the methanol fraction (MeF) from Schinus terebinthifolius on blood parameters of liver function in naive rats.

\begin{tabular}{lcc}
\hline \multirow{2}{*}{ Parameters } & \multicolumn{2}{c}{ Experimental groups } \\
& Saline & MeF \\
\hline AST (UI/L) & $32.49 \pm 1.65$ & $27.16 \pm 3.10$ \\
ALT (UI/L) & $51.57 \pm 1.41$ & $47.00 \pm 1.93$ \\
GGT (UI/L) & $28.50 \pm 3.21$ & $24.45 \pm 4.58$ \\
Total bilirubin (mg/dL) & $2.07 \pm 0.30$ & $2.09 \pm 0.24$ \\
Direct bilirubin (mg/dL) & $1.04 \pm 0.16$ & $1.57 \pm 0.31$ \\
Indirect bilirubin $(\mathrm{mg} / \mathrm{dL})$ & $0.89 \pm 0.19$ & $0.52 \pm 0.10$ \\
\hline
\end{tabular}

Data represent mean \pm SE. $n=6$ rats/group. AST: aspartate aminotransferase, ALT: alanine aminotransferase, and GGT: gamma-glutamyltranspeptidase.

Our study also focused on ROS because of their emerging role in the pain mechanism [9-12]. For the first time, we demonstrated that the administration of an extract from $S$. terebinthifolius induced changes in spinal-cord prooxidant and antioxidant markers. Interestingly, the changes were not exclusive to the MeF-treated CCI rats, but some of them were also present in the saline-treated CCI rats and the saline- and MeF-treated Sham rats. These results suggest that the changes may be more related to the peripheral lesion than to the treatment. However, while the ascorbicacid content increased in the saline-treated CCI rats after 10 days, this content was reduced in the MeF-treated CCI rats at this time point. This decrease suggests that the treatment induced a modulation in ascorbic acid. The increase in the ascorbic-acid content 3 days after CCI may indicate that the modulation of ascorbic acid occurred later. Ascorbic acid is involved in the first line of antioxidant defense in the brain, protecting the lipid membranes and proteins from oxidative damage [35]. Extracellular ascorbic-acid concentrations are increased in response to brain activity [35]. Glutamate and other neurotransmitters are increased in neuropathic pain $[1,2]$. Thus, the increase in ascorbic-acid levels may be related to high synaptic activity in the spinal cord of rats with CCI. The reduction may be related to antioxidant molecules present in the MeF. Ji et al. [36] suggested that scavenging ROS appears to present an opportunity to normalize brain functions associated with pain. Since the MeF treatment did not decrease ascorbic-acid levels after 3 days, this result suggests that the modulation of ascorbic acid by MeF occurs later. Differences in the time of modulation may be related to the dose used in our study. Further studies with high doses of the MeF may help to clarify this suggestion.

When ascorbic acid carries out its antioxidant activity, it becomes oxidized. However, the reduction of its oxidized form is an enzymatic reaction, which may depend on glutathione [35], the most abundant thiol in mammals. Since ascorbic acid was increased in the CCI rats, the use of glutathione to reduce the oxidized form of ascorbic acid may have contributed to the decrease in the total thiols in the spinal cord of the CCI rats. Glutathione is a cofactor for GPx and GST [37]. The reduction in glutathione may explain the decrease in GPx and GST activities. In the Sham rats, the reduction in total thiols may be indicating the effects of these molecules. Total thiols constitute a group of molecules that act as cofactors in some enzymatic systems, and they can directly neutralize radicals [37]. The reduction in total thiols may be due to the important role of the antioxidants in muscle regeneration. Kozakowska et al. [38] demonstrated that oxidative stress is an important modulator of skeletal muscle regeneration after injury. The glutathione reduction may explain the change in GPx and GST activities in Sham rats.

Increased SOD activity was found in the Sham and CCI rats at all time points studied. SOD converts the superoxide anion to $\mathrm{H}_{2} \mathrm{O}_{2}$. Therefore, one would expect an increase in $\mathrm{H}_{2} \mathrm{O}_{2}$ levels in the spinal cord of these animals. In fact, the levels of this molecule increased in the Sham rats treated with saline for 3 and 10 days. This increase may be responsible for the increased CAT activity at day 3. CAT, an enzyme located in peroxisomes, catalyzes the breakdown of $\mathrm{H}_{2} \mathrm{O}_{2}$ to $\mathrm{H}_{2} \mathrm{O}$ and $\mathrm{O}_{2}$ [39]. After muscle injury, the induction of CAT is delayed and the peak of its activity occurs on the 2nd day after injury, followed by thioredoxin activity, which reaches its highest level on day 7 [40]. Thioredoxin is an antioxidant protein that limits the activity of ROS $[39,41]$. With the increase in thioredoxin, CAT activity may be reduced, which explains the decrease in CAT in the saline-treated Sham rats after 10 days. Both glutathione and thioredoxin support enzyme systems for the elimination of peroxides, but each system has different kinetics and functions [41]. Thus, the probable activity of the thioredoxin does not exclude the possibility of a positive effect of the thiols found at day 10.

The presence of antioxidant molecules in the MeF may be responsible for the lack of a significant change in catalase activity in the MeF-treated Sham rats. A similar suggestion may apply to the MeF-treated CCI rats. However, catalase activity was also decreased in the saline-treated CCI rats. We suggest that this result may be related to the use of thiols, which was also decreased in these animals. The use of thiols may be related to the increase in ascorbic acid, as discussed above.

According to Goecks et al. [9], CCI injury, in contrast to the situation in Sham animals, probably mobilizes more antioxidant systems to prevent oxidative stress, given the greater excitation of the central sensory neurons. Since excessive ROS formation must be corrected only to prevent the accumulation of oxidative damage, and a slight prooxidative balance is necessary for optimal cell signaling processes [42], the different excitation of central sensory neurons may be responsible for the differences between the CCI and Sham rats. The mobilization of antioxidant systems may contribute to the absence of a significant change in lipid hydroperoxides in the spinal cord.

The lack of changes in the EPM and OF tests, plasma indicators, and body weight suggests that the MeF has no toxic effect, which raises the possibility that the MeF might be used clinically as an adjuvant to treat neuropathic pain. A recent study indicated that $S$. terebinthifolius has a toxic potential [43]. However, this study administered a treatment for 83 days, and the harmful effects occurred mainly at doses of 176 and $352 \mathrm{mg} / \mathrm{kg}$ body weight. Thus, the dose appears to be an important factor in determining the toxic effect of extracts from this plant. 


\section{Conclusion}

The fractions obtained by successive extractions of dried and powdered leaves from Schinus terebinthifolius, particularly the MeF, contained antioxidant molecules. This is the first demonstration that $\mathrm{MeF}$, in a dose of $20 \mathrm{mg} / \mathrm{kg} / \mathrm{d}$ administered for 3 and 10 days, induces antinociception without apparent toxic effects, which suggests that this fraction could possibly be used to treat neuropathic pain. In addition, this study provided evidence that $\mathrm{MeF}$ administration changes prooxidant and antioxidant markers in the spinal cord, markers that had been altered after a peripheral lesion. We suggest that the changes may be related to antioxidant molecules present in the MeF, because scavenging ROS appears to present an opportunity to help to normalize the spinal-cord oxidative status altered by pain. However, we cannot exclude the possibility that other compounds of the extract may be contributing to antinociceptive effect. Further studies are necessary to better understand the relation between $\mathrm{MeF}$ treatment, antinociception, and oxidative stress parameters in the spinal cord of rats with CCI-induced neuropathic pain.

\section{Conflicts of Interest}

The authors declare that there are no conflicts of interest regarding the publication of this paper.

\section{Authors' Contributions}

Taína Scheid and Wania Aparecida Partata were responsible for the study concept and design and they prepared and wrote the manuscript. Taína Scheid, Maira Silmara Moraes, Thiago Pereira Henriques, Ana Paula Konzen Riffel, and Eduardo Miranda Ethur performed the experiments. Adriane BellóKlein, Gilsane Lino Von Poser, and Eduardo Miranda Ethur provided research material. All authors approved the final manuscript.

\section{Acknowledgments}

This study was supported by grants from Fundação de Amparo à Pesquisa do Estado do Rio Grande do Sul (FAPERGS).

\section{References}

[1] L. Colloca, T. Ludman, D. Bouhassira et al., "Neuropathic pain," Nature Reviews Disease Primers, vol. 3, Article ID 17002, 2017.

[2] F. T. Nickel, F. Seifert, S. Lanz, and C. Maihöfner, "Mechanisms of neuropathic pain," European Neuropsychopharmacology, vol. 22, no. 2, pp. 81-91, 2012.

[3] D. J. Newman and G. M. Cragg, "Natural products as sources of new drugs over the 30 years from 1981 to 2010," Journal of Natural Products, vol. 75, no. 3, pp. 311-335, 2012.

[4] A. C. Piccinelli, J. A. Santos, E. C. Konkiewitz et al., "Antihyperalgesic and antidepressive actions of (R)-(+)-limonene, $\alpha$ phellandrene, and essential oil from Schinus terebinthifolius fruits in a neuropathic pain model," Nutritional Neuroscience, vol. 18, no. 5, pp. 217-224, 2015.
[5] M. P. Corrêa, Dicionário De Plantas Úteis Do Brasil E Das Exóticas Cultivadas, Imprensa Nacional, Rio de Janeiro, Brazil, 1984.

[6] A. S. Jaggi, V. Jain, and N. Singh, "Animal models of neuropathic pain," Fundamental \& Clinical Pharmacology, vol. 25, no. 1, pp. 1-28, 2011.

[7] S. Johann, N. P. Sá, L. A. Lima et al., "Antifungal activity of schinol and a new biphenyl compound isolated from Schinus terebinthifolius against the pathogenic fungus Paracoccidioides brasiliensis," Annals of Clinical Microbiology and Antimicrobials, vol. 9, no. 1, p. 30, 2010.

[8] K. F. El-Massry, A. H. El-Ghorab, H. A. Shaaban, and T. Shibamoto, "Chemical compositions and antioxidant/ antimicrobial activities of various samples prepared from Schinus terebinthifolius leaves cultivated in Egypt," Journal of Agricultural and Food Chemistry, vol. 57, no. 12, pp. 5265-5270, 2009.

[9] C. S. B. Goecks, A. Horst, M. S. Moraes et al., "Assessment of oxidative parameters in rat spinal cord after chronic constriction of the sciatic nerve," Neurochemical Research, vol. 37, no. 9, pp. 1952-1958, 2012.

[10] T. Scheid, L. D. Bosco, R. P. Guedes, M. A. Pavanato, A. BellóKlein, and W. A. Partata, "Sciatic nerve transection modulates oxidative parameters in spinal and supraspinal regions," Neurochemical Research, vol. 38, no. 5, pp. 935-942, 2013.

[11] J. Yowtak, J. Wang, H. Y. Kim, Y. Lu, K. Chung, and J. M. Chung, "Effect of antioxidant treatment on spinal GABA neurons in a neuropathic pain model in the mouse," PAIN, vol. 154, no. 11, pp. 2469-2476, 2013.

[12] A. P. K. Riffel, J. A. de Souza, M. D. C. Q. Santos et al., "Systemic administration of vitamins $\mathrm{C}$ and $\mathrm{E}$ attenuates nociception induced by chronic constriction injury of the sciatic nerve in rats," Brain Research Bulletin, vol. 121, pp. 169-177, 2016.

[13] T. Siatka and M. Kašparová, "Seasonal variation in total phenolic and flavonoid contents and DPPH scavenging activity of Bellis perennis L. flowers," Molecules, vol. 15, no. 12, pp. $9450-$ 9461, 2010.

[14] V. Chobot, "Simultaneous detection of pro- and antioxidative effects in the variants of the deoxyribose degradation assay," Journal of Agricultural and Food Chemistry, vol. 58, no. 4, pp. 2088-2094, 2010.

[15] M. T. K. Dresch, S. B. Rossato, V. D. Kappel et al., "Optimization and validation of an alternative method to evaluate total reactive antioxidant potential," Analytical Biochemistry, vol. 385, no. 1, pp. 107-114, 2009.

[16] H. Wagner and S. Bladt, Plant Drug Analysis: A Thin Layer Chromatography Atlas, Springer, Berlin, Germany, 2nd edition, 1996.

[17] E. C. Rosas, L. B. Correa, T. D. A. Pádua et al., "Antiinflammatory effect of Schinus terebinthifolius Raddi hydroalcoholic extract on neutrophil migration in zymosan-induced arthritis," Journal of Ethnopharmacology, vol. 175, pp. 490-498, 2015.

[18] L. E. S. Fedel-Miyasato, A. S. N. Formagio, S. A. Auharek et al., "Antigenotoxic and antimutagenic effects of Schinus terebinthifolius Raddi in Allium cepa and Swiss mice: a comparative study," Genetics and Molecular Research, vol. 13, no. 2, pp. 34113425, 2014.

[19] O. C. Pires, A. V. C. Taquemasa, G. Akisue et al., "Análise preliminar da toxicidade aguda e dose letal mediana (DL50) comparativa entre os frutos de Pimenta-do-Reino do Brasil 
(Schinus terebinthifolius Raddi) e Pimenta-do-Reino (Pipper nigrum L.)," Acta Farmaceutica Bonaerense, vol. 23, pp. 176-182, 2004.

[20] Z.-Y. Cai, P. Galettis, Y. Lu, D. L. Morris, and M. H. Pourgholami, "Pharmacokinetics of albendazole in New Zealand white rabbits: Oral versus intraperitoneal administration," Anticancer Reseach, vol. 27, no. 1 A, pp. 417-422, 2007.

[21] G. J. Bennett and Y. K. Xie, "A peripheral mononeuropathy in rat that produces disorders of pain sensation like those seen in man," PAIN, vol. 33, no. 1, pp. 87-107, 1988.

[22] M. A. de Souza, L. A. Centenaro, P. R. Menegotto et al., "Prenatal stress produces social behavior deficits and alters the number of oxytocin and vasopressin neurons in adult rats," Neurochemical Research, vol. 38, no. 7, pp. 1479-1489, 2013.

[23] H. P. Misra and I. Fridovich, "The role of superoxide anion in the autoxidation of epinephrine and a simple assay for superoxide dismutase.", The Journal of Biological Chemistry, vol. 247, no. 10, pp. 3170-3175, 1972.

[24] H. Aebi, "[13] Catalase in vitro," Methods in Enzymology, vol. 105, pp. 121-126, 1984.

[25] L. Flohe and W. A. Gunzler, "Assays of glutathione peroxidase," Methods in Enzymology, vol. 105, pp. 114-121, 1984.

[26] B. Mannervik and C. Guthenberg, "[28] Glutathione transferase (human placenta)," Methods in Enzymology, vol. 77, pp. 231-235, 1981.

[27] J. H. Roe and C. A. Kuether, "The determination of ascorbic acido in whole blood and urine through the 2,4dinitrophenylhydrazine derivative of dehydroascorbic acid," The Journal of Biological Chemistry, vol. 147, pp. 399-407, 1943.

[28] M. Y. Aksenov and W. R. Markesbery, "Changes in thiol content and expression of glutathione redox system genes in the hippocampus and cerebellum in Alzheimer's disease," Neuroscience Letters, vol. 302, no. 2-3, pp. 141-145, 2001.

[29] E. Pick and Y. Keisari, "A simple colorimetric method for the measurement of hydrogen peroxide produced by cells in culture," Journal of Immunological Methods, vol. 38, no. 1-2, pp. 161-170, 1980.

[30] Z.-Y. Jiang, A. C. S. Woollard, and S. P. Wolff, "Lipid hydroperoxide measurement by oxidation of $\mathrm{Fe}^{2+}$ in the presence of xylenol orange. Comparison with the TBA assay and an iodometric method," Lipids, vol. 26, no. 10, pp. 853-856, 1991.

[31] O. H. Lowry, N. J. Rosebrough, A. L. Farr, and R. J. Randall, "Protein measurement with the Folin phenol reagent.," The Journal of Biological Chemistry, vol. 193, no. 1, pp. 265-275, 1951.

[32] A. Muthuraman and N. Singh, "Neuroprotective effect of saponin rich extract of Acorus calamus L. in rat model of chronic constriction injury (CCI) of sciatic nerve-induced neuropathic pain," Journal of Ethnopharmacology, vol. 142, no. 3, pp. 723-731, 2012.

[33] M. K. Jain, Bao-Zhu Yu, J. M. Rogers et al., "Specific competitive inhibitor of secreted phospholipase A2 from berries of Schinus terebinthifolius," Phytochemistry, vol. 39, no. 3, pp. 537-547, 1995.

[34] C. C. Câmara, H. F. Ramos, A. P. da Silva et al., "Oral gabapentin treatment accentuates nerve and peripheral inflammatory responses following experimental nerve constriction in Wistar rats," Neuroscience Letters, vol. 556, pp. 93-98, 2013.

[35] A. Covarrubias-Pinto, A. I. Acuña, F. A. Beltrán, L. Torres-Díaz, and M. A. Castro, "Old things new view: ascorbic acid protects the brain in neurodegenerative disorders," International Journal of Molecular Sciences, vol. 16, no. 12, pp. 28194-28217, 2015.
[36] G. Ji, Z. Li, and V. Neugebauer, "Reactive oxygen species mediate visceral pain-related amygdala plasticity and behaviors," PAIN, vol. 156, no. 5, pp. 825-836, 2015.

[37] H. Sies, "Glutathione and its role in cellular functions," Free Radical Biology \& Medicine, vol. 27, no. 9-10, pp. 916-921, 1999.

[38] M. Kozakowska, K. Pietraszek-Gremplewicz, A. Jozkowicz, and J. Dulak, "The role of oxidative stress in skeletal muscle injury and regeneration: focus on antioxidant enzymes," Journal of Muscle Research and Cell Motility, vol. 36, no. 6, pp. 377-393, 2015.

[39] S. K. Powers, L. L. Ji, A. N. Kavazis et al., "Reactive oxygen species: impact on skeletal muscle," Comprehencive Physiology, vol. 1, pp. 941-969, 2011.

[40] S. Singh, D. C. Canseco, S. M. Manda et al., "Cytoglobin modulates myogenic progenitor cell viability and muscle regeneration," Proceedings of the National Acadamy of Sciences of the United States of America, vol. 111, no. 1, pp. E129-E138, 2014.

[41] D. P. Jones, "Radical-free biology of oxidative stress," American Journal of Physiology-Cell Physiology, vol. 295, no. 4, pp. C849C868, 2008.

[42] B. Poljsak, D. Šuput, and I. Milisav, "Achieving the balance between ROS and antioxidants: when to use the synthetic antioxidants," Oxidative Medicine and Cellular Longevity, vol. 2013, Article ID 956792, pp. 1-11, 2013.

[43] E. A. Carlini, J. M. Duarte-Almeida, and R. Tabach, "Assessment of the toxicity of the Brazilian pepper trees Schinus terebinthifolius Raddi (Aroeira-da-praia) and Myracrodruon urundeuva Allemão (Aroeira-do-sertão)," Phytotherapy Research, vol. 27, no. 5, pp. 692-698, 2013. 


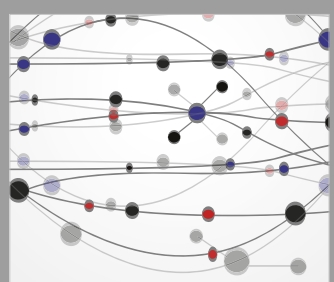

The Scientific World Journal
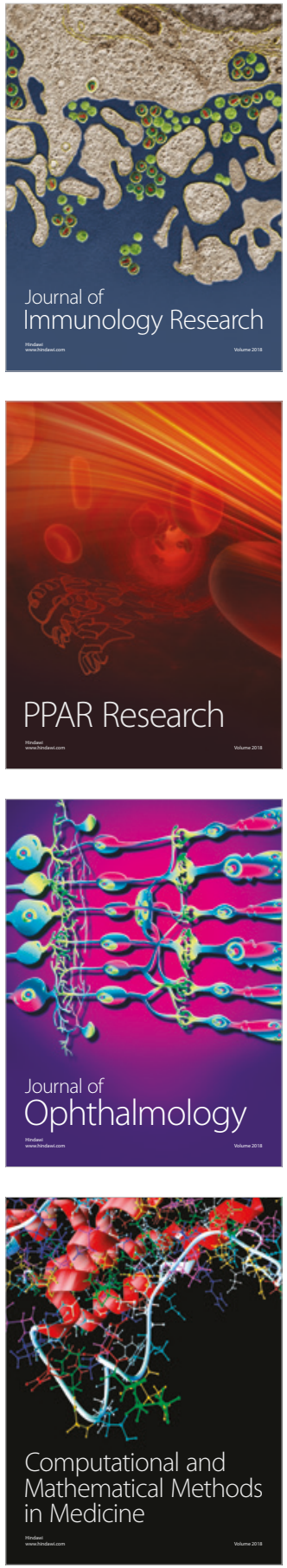

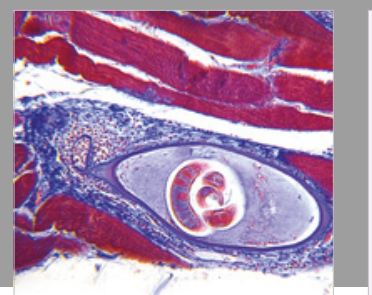

Gastroenterology Research and Practice

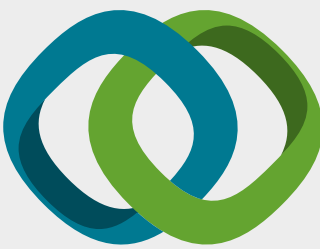

\section{Hindawi}

Submit your manuscripts at

www.hindawi.com
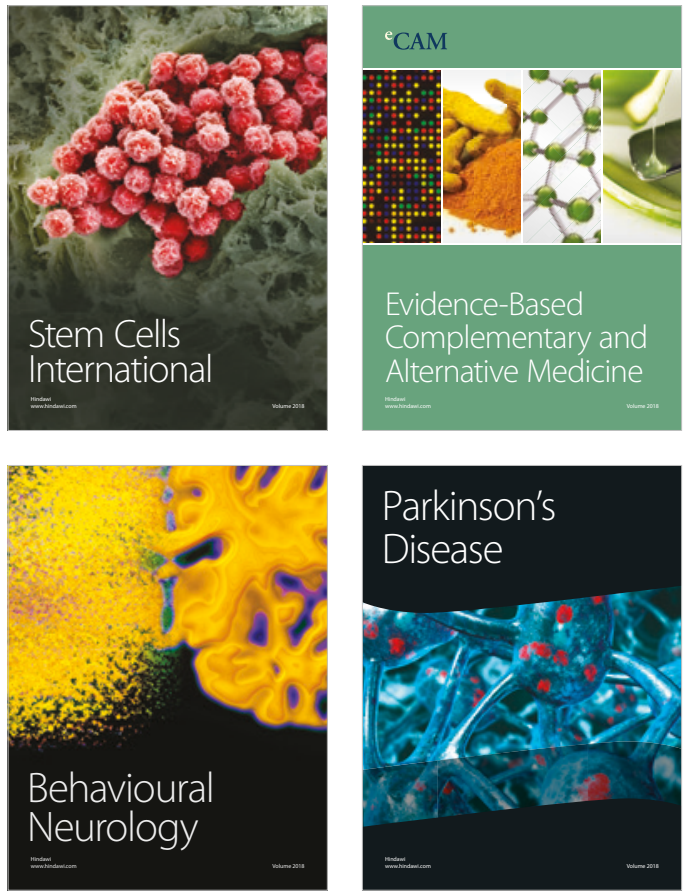

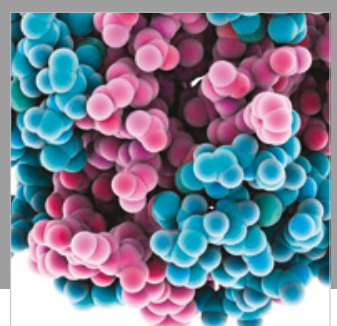

ournal of

Diabetes Research

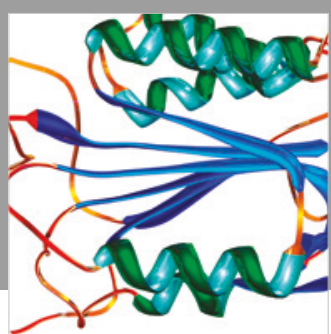

Disease Markers
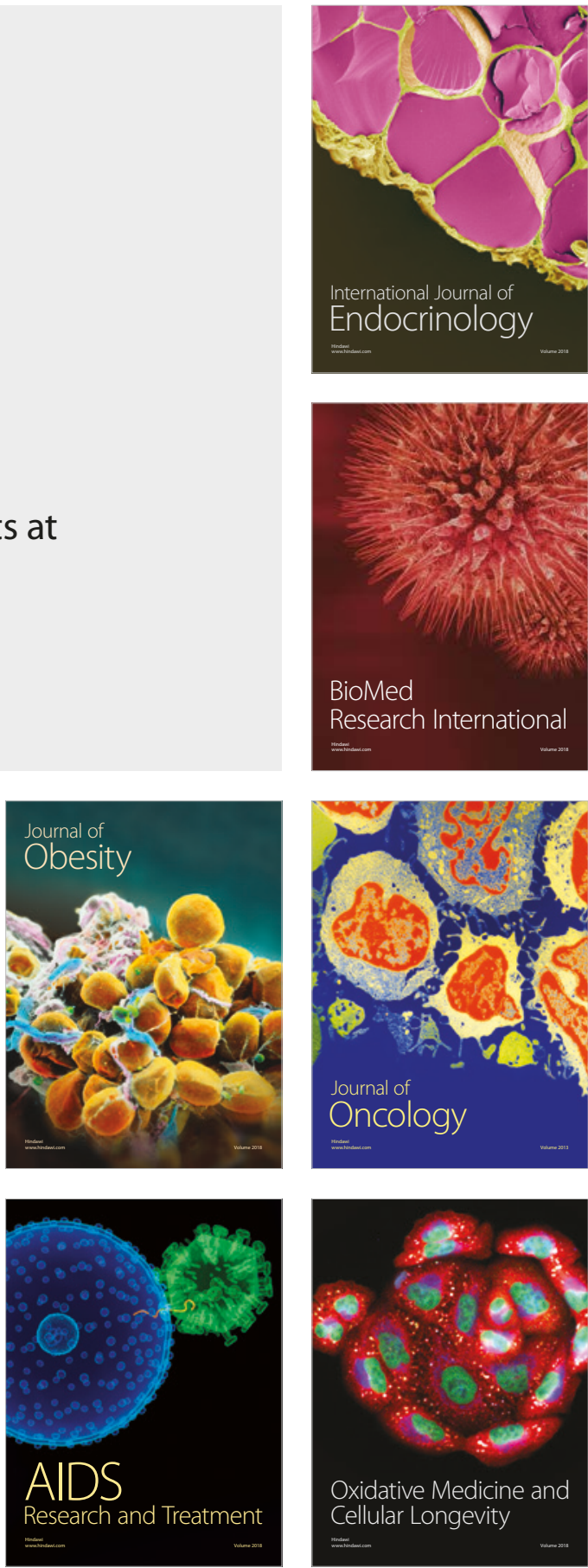